\title{
Immune thrombocytopenia: vaccination does not equal causation
}

\author{
Allyson Pishko ${ }^{1}$ and Adam Cuker ${ }^{1,2}$ \\ ${ }^{1}$ Department of Medicine, Perelman School of Medicine, University of Pennsylvania and ${ }^{2}$ Department of Pathology $\&$ Laboratory \\ Medicine, Perelman School of Medicine, University of Pennsylvania, Philadelphia, PA, USA
}

E-mail: ADAM CUKER - Adam.Cuker@pennmedicine.upenn.edu

doi:10.3324/haematol.2021.279727

V accination is the most important tool available for decreasing the incidence of severe disease and death due to severe acute respiratory syndrome coronavirus2 (SARS-CoV-2). ${ }^{1}$ Early case reports and media coverage of patients diagnosed with immune thrombocytopenia (ITP) after receipt of a SARS-CoV-2 vaccine raised concern among patients and providers. ${ }^{2}$ In this issue of Haematologica, Choi et al. describe the clinical course of a series of patients with a diagnosis of ITP in the 6 weeks following SARS-CoV-2 vaccination as identified by a national survey of hematologists in Australia. ${ }^{3}$ Patients with features of the more lethal and rare vaccine-related phenomenon, vaccine-induced immune thrombotic thrombocytopenia, were excluded. ${ }^{3}$

At the time of this writing, 4.48 billion patients worldwide have received at least one dose of a SARS-CoV-2 vaccine. ${ }^{4}$ It is now increasingly apparent from large epidemiological studies that if there is an association with vaccination and ITP, the overall incidence is low (Table 1).$^{5-7}$ In the study in this issue, Choi et al. explicitly do not set out to describe the incidence of ITP following vaccination nor determine causality. However, it is reassuring that only 14 patients (10 de novo cases) were identified with ITP in this survey of hematologists across Australia. ITP is not a particularly uncommon diagnosis, with an estimated incidence rate of three cases of primary ITP diagnosed per 100,000 adults per year. ${ }^{8}$ Given that 4.2 million adults in Australia had been vaccinated at the time of the study by Choi et al., we would expect about 126 of these individuals to be newly diagnosed with ITP during the ensuing 12 months by chance alone, regardless of vaccination status. Using this estimate, we would anticipate roughly 15 individuals to be newly diagnosed with ITP during any 6-week period, whether they received vaccination or not. This simplified analysis does not take into account seasonal variation in the incidence of ITP or differences in incidence based on age or gender. ${ }^{8,9}$ Nonetheless, the number of new cases of ITP $(n=10)$ identified by Choi et al. in the 6 weeks following SARS-CoV-2 vaccination is in line with this expected incidence, suggesting that some or all of the cases identified by the authors may have occurred in proximity to vaccination purely by chance.

While we cannot conclude causality from the study, it is certainly plausible that vaccination could trigger an ITP episode. Any stimulus to the immune system may theoretically induce production of platelet auto-antibodies, as has been observed with certain pathogens and with live vaccines, including the measles vaccine. ${ }^{10}$

The study by Choi et al. provides important details regarding the clinical course of ITP following SARS-CoV-2 vaccination. Most cases responded rapidly to standard first-line therapies (corticosteroids, intravenous immunoglobulin), as would be expected in adults with garden-variety primary ITP. This experience suggests that patients who are diagnosed with ITP in proximity to SARS-CoV-2 vaccination may generally be treated with standard ITP therapy.

With the rampant increase in the delta variant of SARSCoV-2, it is all the more important to instill confidence in the safety of vaccines, while also being careful to not be dismissive of safety concerns. The study by Choi et al. adds to literature reinforcing the safety of the SARS-CoV-2 vaccines by demonstrating that occurrence of ITP following vaccination is uncommon, perhaps no greater than what would be expected to occur purely by chance, and that most cases are treatable with standard first-line therapies. Patients with known ITP should be counseled to monitor for signs/symptoms of recurrence (e.g., petechiae, mucosal bleeding) after vaccination. Clinicians may consider obtaining platelet counts, particularly in patients without stable counts, before and after vaccination. Overall, the benefits of vaccination against COVID-19 continue to vastly outweigh the risks in patients with ITP and in the population at large.

\section{Disclosures}

$A M P$ receives research funding from Novo Nordisk and Sanofi Genzyme. AC has served as a consultant for Synergy, has received

Table 1. Incidence of immune thrombocytopenia following SARS-CoV-2 vaccination from selected epidemiological studies.

\begin{tabular}{|c|c|c|c|c|c|}
\hline Study & Vaccine & Definition of ITP & Population & Incidence & Relative risk \\
\hline Simpson et al..$^{5}$ & ChAdOxl & $\begin{array}{l}\text { Diagnosis code } \\
\text { (read code) }\end{array}$ & $\begin{array}{l}\text { Age } \geq 18 \\
\text { Scotland }\end{array}$ & $\begin{array}{c}1.13(95 \% \text { CI } 0.62-1.63) \\
\text { cases per } \\
100,000 \text { vaccinations }\end{array}$ & $\begin{array}{c}\text { aRR } 5.77 \\
(95 \% \text { CI 2.41-13.83)* }\end{array}$ \\
\hline Simpson et al..$^{5}$ & BNT162b2 & $\begin{array}{l}\text { Diagnosis code } \\
\text { (read code) }\end{array}$ & $\begin{array}{l}\text { Age } \geq 18 \\
\text { Scotland }\end{array}$ & NR & $\begin{array}{c}\mathrm{aRR} 0.54 \\
(95 \% \text { CI } 0.1-3.02)^{*}\end{array}$ \\
\hline Pottegard et al. ${ }^{6}$ & ChAdOxl & $\begin{array}{l}\text { Diagnosis code } \\
\text { (ICD-10) }\end{array}$ & $\begin{array}{c}\text { Age 18-65 years, } \\
\text { Denmark and Norway }\end{array}$ & $\begin{array}{c}<5 \text { cases out of } \\
281,264 \text { first doses }\end{array}$ & $\mathrm{NR}$ \\
\hline Welsh et al. ${ }^{7}$ & $\begin{array}{l}\text { BNT162b2 or } \\
\text { mRNA-1273 }\end{array}$ & $\begin{array}{l}\text { VAERS report of } \\
\text { thrombocytopenia } \\
\text { (did not specify ITP) }\end{array}$ & $\begin{array}{c}\text { Adults, } \\
\text { USA }\end{array}$ & $\begin{array}{l}0.8 \text { cases per } \\
\text { million doses }\end{array}$ & NR \\
\hline
\end{tabular}

ITP: immune thrombocytopenia; 95\% CI: confidence interval; aRR: adjusted relative risk; NR: not reported;VAERS:Vaccine Adverse Event Reporting System. *Adjusted relative risk of ITP occurring 0-27 days after vaccination. 
royalties from UpToDate, and his institution has received research support on his behalf from Alexion, Bayer, Novartis, Novo Nordisk, Pfizer, Sanofi, and Spark.

\section{Contributions}

Both authors contributed equally.

\section{References}

1. Bernal JL, Andrews N, Gower C, et al. Effectiveness of Covid-19 vaccines against the B.1.617.2 (delta) variant. New Engl J Med. 2021;385(7):585-594.

2. Lee E, Cines DB, Gernsheimer T, et al. Thrombocytopenia following Pfizer and Moderna SARS-CoV-2 vaccination. Am J Hematol. 2021;96(5):534-537.

3. Choi PY, Hsu D, Tran HA, et al. Immune thrombocytopenia following vaccination during the COVID-19 pandemic. Haematologica. 2022;107(5):1193-1196.

4. Ritchie H, Ortiz-Ospina E, Beltekian D, et al. Coronavirus pandemic
(COVID-19). https://ourworldindata.org/coronavirus.

5. Simpson CR, Shi T, Vasileiou E, et al. First-dose ChAdOx1 and BNT162b2 COVID-19 vaccines and thrombocytopenic, thromboembolic and hemorrhagic events in Scotland. Nat Med. 2021;27(7):12901297.

6. Pottegård A, Lund LC, Karlstad $\varnothing$, et al. Arterial events, venous thromboembolism, thrombocytopenia, and bleeding after vaccination with Oxford-AstraZeneca ChAdOx1-S in Denmark and Norway: population based cohort study. BMJ. 2021;373:n1114.

7. Welsh KJ, Baumblatt J, Chege W, Goud R, Nair N. Thrombocytopenia including immune thrombocytopenia after receipt of mRNA COVID19 vaccines reported to the Vaccine Adverse Event Reporting System (VAERS). Vaccine. 2021;39(25): 3329-3332

8. Schoonen WM, Kucera G, Coalson J, et al. Epidemiology of immune thrombocytopenic purpura in the General Practice Research Database. Br J Haematol. 2009;145(2):235-244

9. Moulis G, Guénin S, Limal N, et al. Seasonal variations of incident primary immune thrombocytopenia in adults: an ecological study. Eur Intern Med. 2017;37:e26-e28.

10. Cines DB, Bussel JB, Liebman HA, Prak ETL. The ITP syndrome: pathogenic and clinical diversity. Blood. 2009;113(26):6511-6521. 